\title{
Quantitative risk assessment and safety databases in Romanian coal mining: preliminary systematic approach
}

\author{
Gabriel - Victor Vasilescu ${ }^{1}$, Roland Iosif Moraru ${ }^{1 *}$, and Gabriel Bujor Băbuț ${ }^{1}$ \\ ${ }^{1}$ University of Petroşani, Faculty of Mines, 332006 Petroşani, Romania
}

\begin{abstract}
Risk management is becoming increasingly more complex. Risk assessment, approached quantitatively, requires a factual database to define the likelihood of adverse health effects of workplace-related injuries and exposures, and it attempts to balance scientific knowledge with concerns of staff, investigators and administration. Practical guidance should be provided for Romanian coal mining companies to make progress in risk assessment process. Guidance is given on how to effectively introduce quantitative risk assessment in mining industry, the main goal being to highlight that the most valuable resource remains experience gained by effectively performing the process. Analyzing how various parameters are described/used, the paper aims to establish the place and role of quantitative risk analysis mining. Possibilities of developing safety/reliability database in coal mining are investigated. The block diagram describing the conceptual structure of a database on failures, safety of equipment and workers in the mining industry was developed. Because mining relies heavily on complex technologies - permanent mining facilities and large mobile equipment and support services - often located in isolated and hostile environments, the implementation of quantitative risk analysis and the development of a realistic database could be considered as a resilience business strategy and conversion of available knowledge into management actions.
\end{abstract}

\section{Introduction}

At present, the Romanian mining industry does not frequently use quantitative methods to analyze specific hazards and risks, many of which are considered to be risks with potentially catastrophic consequences [1], [2].

Despite their widespread use, qualitative methods of risk analysis suffer from a number of limitations. For example, the use of qualitative language to describe hazards and risks creates an inherent subjectivism of assessments [3]. The uncertain outcome combined with the natural or statistical variability in the available information, often insufficient, further

* Corresponding author: roland moraru@yahoo.com 
complicates predictions, scenarios and comparisons, especially in relation to events with catastrophic consequences, which are so often associated with mining. [4].

Lack of people's experience, perceptions and assumptions, especially during periods of skills shortages and high staff turnover are also part of the associated dilemma. While other high-risk industries have successfully established a number of Quantitative Risk Analysis (QRA) databases, which are firmly embedded in risk management and their competency repertoire, the country's coal mining industry does not have such tools [5], [6].

Considering the similar or even greater field of manifestation of hazards, high risk and the nature of costs in coal mining, we can appreciate the analysis of the opportunity and feasibility of establishing databases to facilitate the application of quantitative risk analysis methods in coal mining work processes should be an assumed goal of decision-makers in the field [7-9].

\section{On the need of quantitative risk assessment in mining}

Various methods of qualitative risk assessment can be easily applied to a variety of risk analysis problems, finding their widespread use throughout the coal industry. However, being qualitative and based on the use of words and language to formulate the problem, their effectiveness depends considerably on the knowledge of the work team. The resulting human subjectivism and, implicitly, the variability and uncertainty in hypotheses, mean that these methods are often insufficient to complete and accurately model the critical relationships, dependencies, and complexity that lead to system hazards and potential risks with catastrophic consequences on occupational safety and health [10].

Semi-quantitative methods allow some risk comparisons to be numerically relative, but do not provide the possibility to develop a complete and detailed assessment of the functional safety of a work system. Also, qualitative and / or semi-quantitative methods are not able to model and evaluate the effects of two or more malfunctions at the same time, the common cause of failures and errors that may affect several parts of the system or the benefits that redundancy can bring to the system safety. One of their key shortcomings is the inability to be used effectively in modeling and predicting the low frequency of occurrence of events with serious consequences. Examples of quantitative methods of risk assessment include, amongst others: Fault Tree Analysis (FTA), Event Tree Analysis (ETA), Layer of Protection (LOPA), First Order Reliability (FOIM) method, Bayesian networks, Monte Carlo simulation, and other mathematical methods [11].

As suggested in the block diagram shown in fig. 1, quantitative assessments overcome many of the above shortcomings and are adapted to situations where adequate data are available during the design, operation, maintenance or modification of a technical or work system.

The results of quantitative analyzes can be used in cost-benefit studies and in demonstrating that the risks to employees, industry, society and the environment are as low as rationally possible (ALARP concept), especially when the assessment relates to the risks with catastrophic consequences, which can be prevented defensively only by quantitative analysis [12]. The advantages of quantitative approaches over qualitative methods are that they can be adapted for specific applications and are able to reflect even fine nuances of the investigation, thus providing a management with fewer decision parameters. 


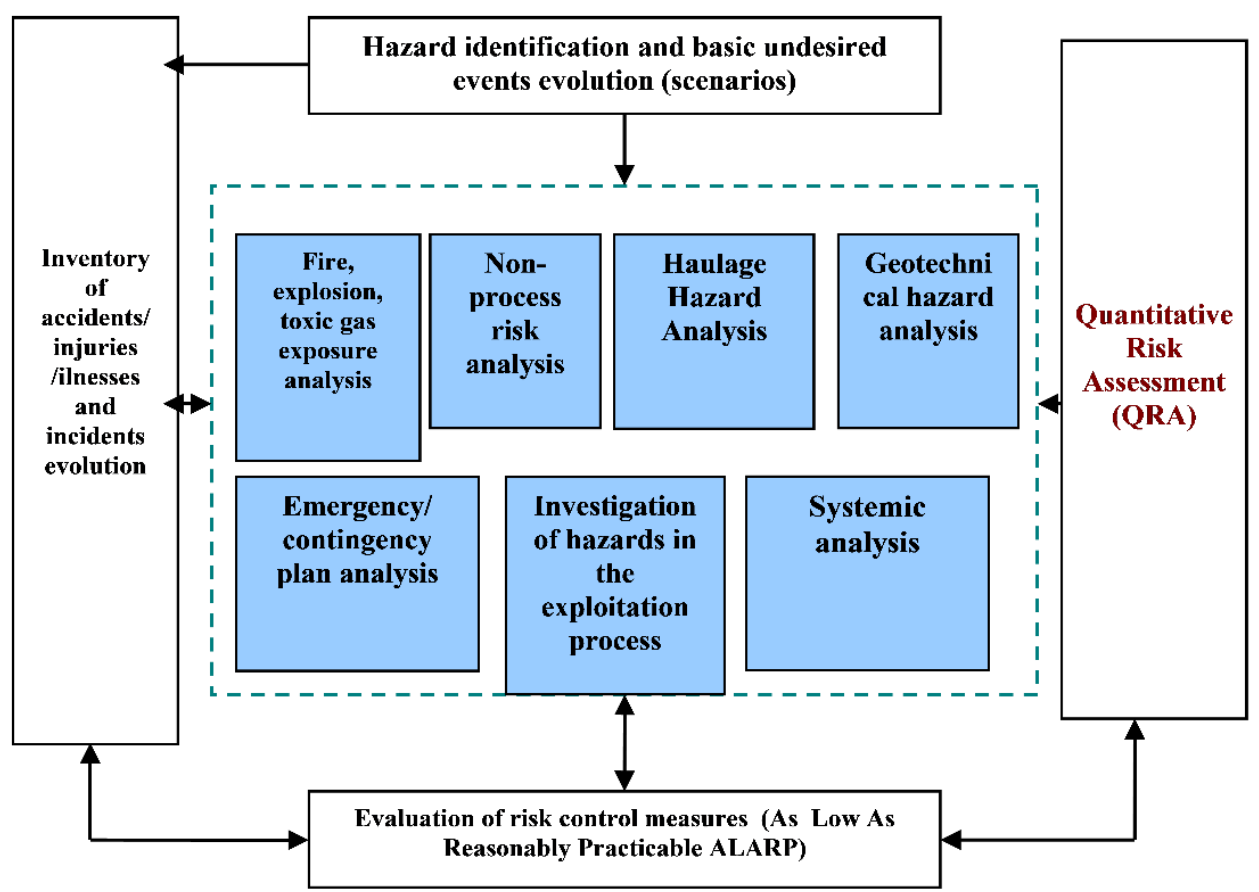

Fig. 1. The place and role of quantitative risk analysis in the mining industry

The use of performance data objectively helps to evaluate and compare complex technological systems, to test and evaluate changes in adaptability in design, operation and maintenance. This approach is appropriate to identify system vulnerabilities and mitigation strategies to reduce risk exposure. Modeled correctly and efficiently, changes can be simulated before being put into practice. Quantitative assessments have their origins in high-risk industries such as the petrochemical industry, the nuclear or aviation sector and include many reliability-based engineering methods. They are also used in many other methodologies, such as fire and explosion engineering, epidemiological health studies, or other fields of science that use mathematical models to study the hazards and risk associated with them [13-15].

If initially the main goal was to analyze technical systems, some sectors, such as the nuclear and aviation sector, also detailed the analysis of human safety which, together with technical reliability and performance data are able to model the safety of the resulting manmachine system. Exclusively probabilistic methods, such as the "First Order Reliability Method" (FOIM) are of the most complex type, being used for quantitative risk analysis. The advantage of the FOIM method over any other method is the ability to successfully cope with the statistical uncertainty of the data. The results obtained by the FOIM method provide additional information on the vulnerability of the system depending on the variability of the input data. The advantage is that erroneous data can be synthesized from basic technical data by adapting design calculations, which can then be used to support the application of other techniques such as Fault Tree Analysis [11].

Analysis using Monte Carlo simulation is more common than FOIM also due to its intuitive approach. It has found wide applicability in many fields, such as engineering and finance. Many systems are too complex for the effects of uncertainty to be modeled using analytical techniques, but can be evaluated by considering inputs as random variables and performing a number of " $n$ " calculations (simulations) by sampling the input to obtain " $n$ " possible values of the desired result. Systems can be developed using tables and other 
conventional tools, but there are easily to found other more sophisticated tools that can meet more complex requirements, many of which are available at affordable prices. When this technique was first developed, the number of iterations imposed by Monte Carlo simulations made the process cumbersome and time-consuming, but computer progress and theoretical developments, such as Latin-hypercube sampling, drastically reduced processing time for most applications [16].

The Monte Carlo simulation method provides a means of assessing the effect of uncertainty in systems in a wide range of situations. It is usually used to evaluate the range of possible results and the relative frequency of values in the respective range for quantitative measurements of a system such as cost, duration, material consumption, demand and other similar measurements [17-20].

\section{Analysis of taxonomy and challenges of setting up databases for quantitative risk analysis applications}

Although quantitative analysis cannot provide absolute safety indicators, the key advantage of quantitative analysis is the relative comparison of two or more risk models between them [21].

To do this, safety engineers need an appropriate combination of frequencies and consequences as inputs to the safety system model. In other words, two main types of input data are required, namely:

- the frequency of "events", or an equivalent numerical descriptor, such as the average time to failure, the probability of failure (PF) or the failure rate;

- the severity of the consequences that describe the credible results related to the events, or the failure of an element, or of the system.

Given the importance of human involvement in most systems, human error estimates should also be available and used in the modeling process. The coal mining industry does not have such data, which has limited QRA-type approaches. [22]. Because even simple systems can contain several thousand elements, all databases usually use a hierarchical system, hereinafter referred to as taxonomy, to create order and logic among the constituent elements. The taxonomy is intended to facilitate data collection, as well as the analysis and subsequent storage of data. It follows that the quality of the data will determine the quality of the risk analysis. One of the key elements of taxonomy is a clearly defined definition of equipment, or work system. This means that all interfaces with the external environment must be identified. If this is done, the faults and consequences within the system can be made explicit. The intention here is one of resolution, ranging from a "part of the part" representing the elementary level, for example, a spring, a tire or the O-ring, to an entire system, which is a collection of several layered components, arranged for perform a specific function, such as a ventilation system, vehicle braking system, dragline or fuel tank, pumping system or haulage equipment.

Understanding risk requires knowledge of its structure and its manifestation. Consequently, we must penetrate into its complexity and into all areas of knowledge [23]. This requires a broad and sometimes complex approach, but, paradoxically, there is no progress to increase the efficiency of productive activities and the well-being of workers without any risk [24]. This progress is increasingly leading to a rejection of the "imposed" risks resulting from human activities in work processes. In the field of occupational safety and health, we will retain the term of failure in case of malfunction of a technical component and the term of human error in case of human component. Figure 2 shows the proposed model. 


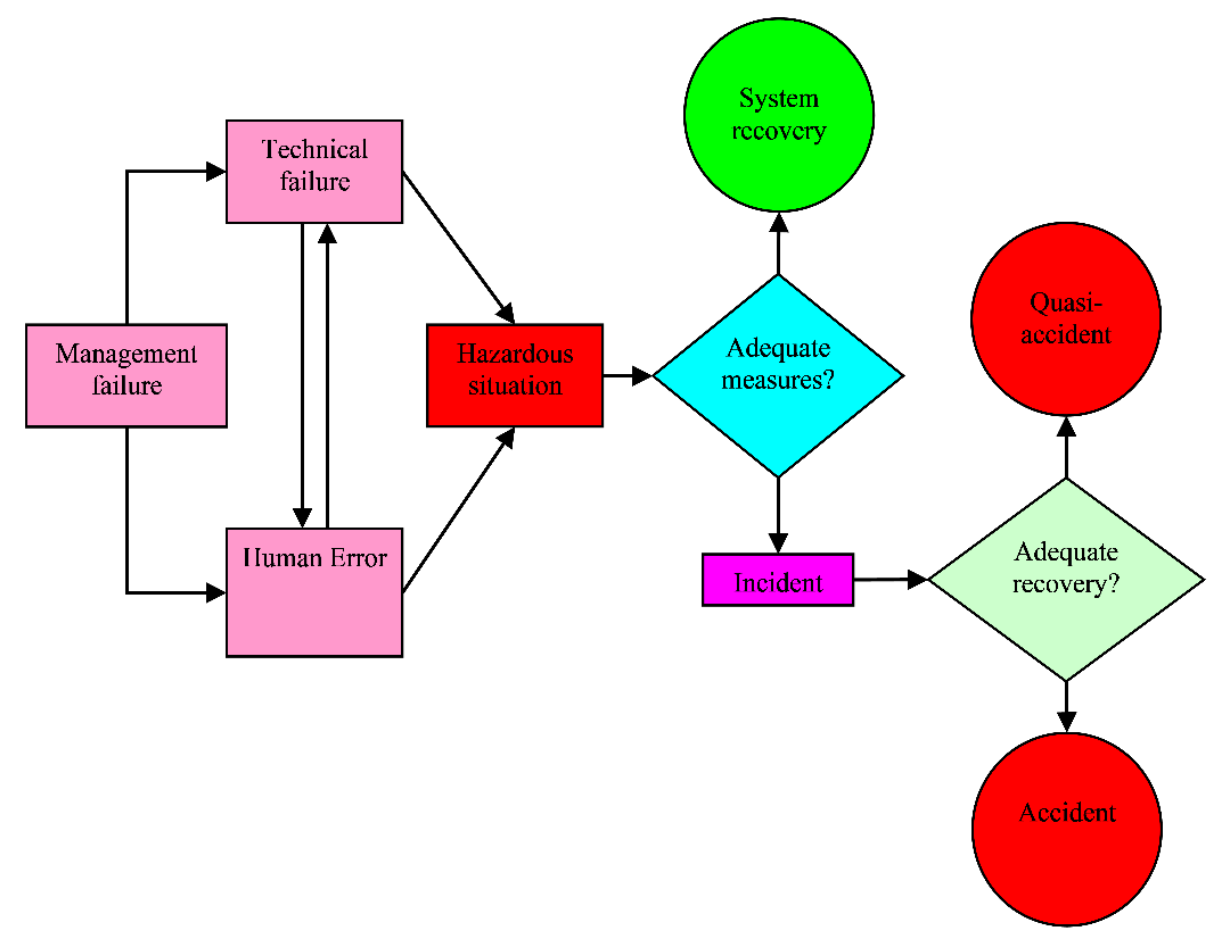

Fig. 2. Chain of events leading to accident occurrence [17]

From the global analysis of unwanted events a structural image of this category of events can be formed. This analysis suggests that all events have the same structure. Undesirable events can be considered as an association of sets of dysfunctions with certain characteristics (figure 3 ).

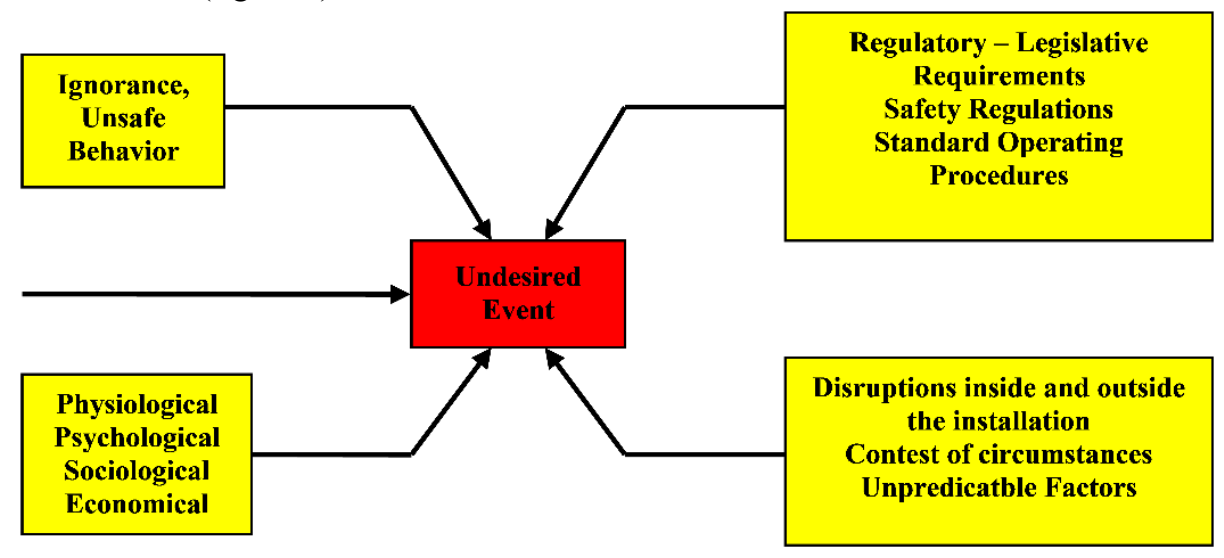

Fig. 3. The structure of dysfunctions that can generate an unwanted event [17]

i. dysfunctions in knowing the risks, which can be divided into two subassemblies: ignorance and unconsciousness. 
ii. legislative dysfunctions, concerning regulations (national, European, international), safety norms that have the value of law, construction rules (welding, reinforced concrete, metal structures) and instructions that describe the operations performed;

iii. technical malfunctions. These are relatively easier to predict because work systems are conceived, designed, built and operated by people;

iv. the human factor. It has different origins that can be physiological in nature, psychological and sociological behavior, or related to economic constraints. Special attention must be paid to human dysfunctions, as the human operator is the central element of safety. Man is targeted in two ways: both as a potential victim of an accident and as a source of insecurity or guarantor of security. Consequently, the modeling of human behavior plays a role of paramount importance in the analysis of associated dysfunctions and in the integration of the results of this analysis in the global evaluation of the work system;

v. randomness and, especially, disturbances from the internal or external context (environment) of the system.

The categories of knowledge required and the safety techniques to be considered in the risk analysis are shown in the diagram in Figure 4.

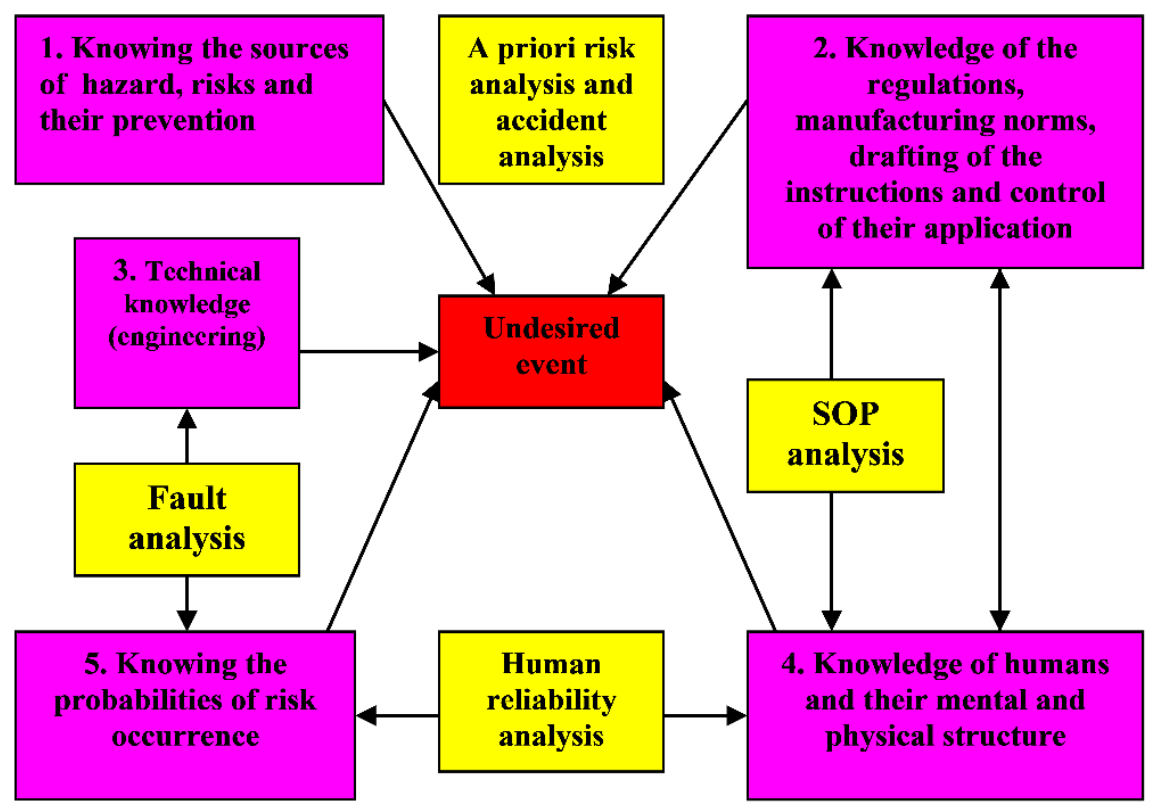

Fig. 4. Categories of knowledge required for risk analysis

It should be noted that the effort and maintenance cost required to maintain a detailed database can generate significant maintenance costs. Careful decisions will be needed to maximize the depreciation of generic databases that are less suitable for applications outside the original domain for which they were established. Considerable problems are also generated by the uncertainties and variability associated with the available data. If not all database providers apply the same strict taxonomy and rigor, uncertainties will spread to the resulting cumulative database, which will then adversely affect the safety or reliability studies. 


\section{Investigating the possibility of developing a safety and reliability database in the coal mining industry}

Currently, there is no publicly available database in Romania that can be used for a Quantitative Risk Analysis (QRA) in mining. To perform a quantitative risk assessment on a mining operation, personnel may use facility data or equipment manufacturer data when available to establish a realistic model of the facility, its reliability or safety. This data can be stored in the maintenance management system and equipment scheduling systems, but if a strict taxonomy has not been used, the data may require prior processing before it can be analyzed and used in a QRA application [25-27].

Other sources of data in mining industry are the incident / accident reporting system and, if any, the "Hazard Register" implemented by many mines worldwide, as well as the Human Resources system that tracks the number of hours worked. In combination, they may be able to provide some frequency-related information, but are probably best used to determine the likely consequences of an event.

The key to data collection is a flexible taxonomy, which can be implemented in any mining operation, regardless of the local systems used. A diagram of the block-scheme structure of the proposed system, with inputs, processes and results is presented in Figure 5.

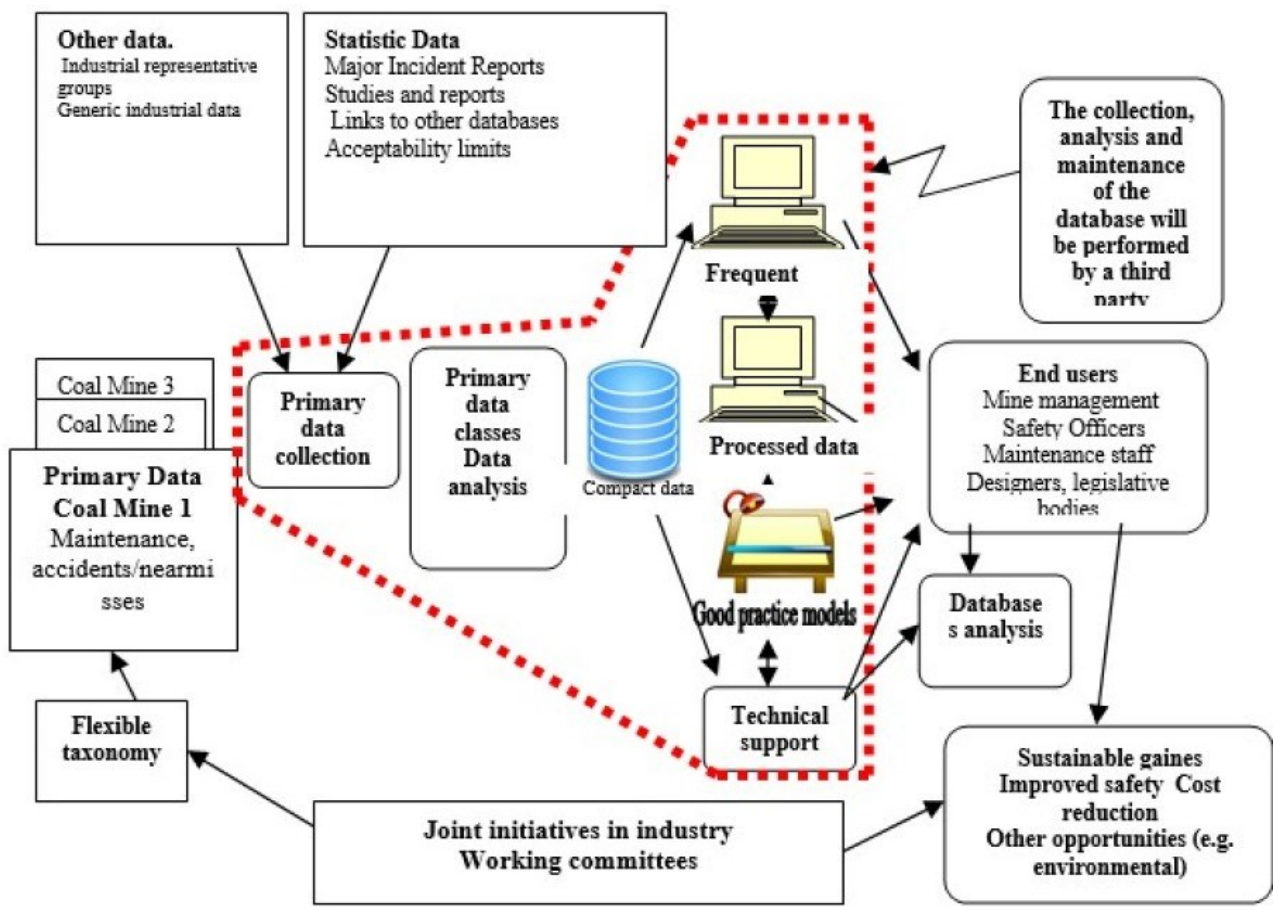

Fig. 5. Conceptual structure of a database on failures, safety of equipment and work in the mining industry

In order to create a reliable and comprehensive system for applying the QRA in the mining industry, an approach is recommended that uses a database system that should meet the following requirements:

a) to be the primary source of information for equipment safety and human safety in the mining industry; 
b) to provide a reliable source for quantifying independently generated equipment failures;

c) to include incidents' frequency and occurred accident severity data, including critical safety system data for any mining application;

d) to be a central register of all incident and accident investigations, as a valuable source of data;

e) to enable the provision of causal models for incidents and accidents, as well as a tool for education in risk management.

Building a reliable database in the mining industry can also provide an opportunity to create a set of best practices, formalized document templates to facilitate faster adoption of quantitative risk analysis. These formalized documents could also help equipment manufacturers achieve more efficient models in a shorter period of time.

Quantitative risk analysis should also consider human error information as another source of technical information, in order to obtain optimal design solutions. Due to the relatively high percentage of adverse events related to human error, proper examination of human actions and behavior can bring the greatest improvements in safety and performance at work. Given its ability to efficiently model dependencies (human-machine interface), this can best be achieved through quantitative risk analysis. The introduction of quantitative analysis, the creation of databases, models of formalized documents, etc. must also include the provision of adequate training and the continuous development of a safety culture for mining companies to participate and lead this new branch of risk analysis and operations management. The training must cover both human errors and technical failures, including some statistical issues. Failure to support training and education requirements will delay the introduction of quantitative risk analysis and will lead, at best, to low cost performance and improved quality of work environment and safety of underground personnel. In the worst case, it will lead to unsafe models, which are potentially dangerous.

\section{Conclusions}

1. Risk analysis is an essential tool for the safety policy of a mining company and its main purpose is to eliminate the potential for injury or damage in productive activity (such as coal mining). The diversity of risk analysis procedures is such that there are several techniques suitable for any circumstance.

2. Risk estimation is probably the most important part of the whole risk assessment procedure, and especially in underground mining operations, if the working conditions are unstable (methane, endogenous fires, coal dust, etc.). We can consider risk as a quantity that can be assessed and expressed through a mathematical relationship, using data collected from real accidents. While considerable improvements have been made in mine safety through risk-based legislation and proactive management of resulting hazards and risks, the mining industry is not really involved in quantitative risk analysis as is the case in other high-risk industries. Using quantitative risk analysis, these industries have successfully improved safety performance by better understanding specific hazards. Constantly applied quantitative analysis offers, compared to a qualitative approach, the unique advantage by which system safety and operational performance of engineering systems can be objectively and explicitly assessed.

3 . The reluctance of the mining industry to adopt quantitative analysis is surprising for two reasons. First, the mining industry, by its dynamic nature, has at least an equal or greater number of hazards and risks than other comparable industries. Some of them are addressed in the current legislation as "main risks" and by their nature lend themselves to a more rigorous hazard and risk analysis, as well as to the investigation of the effectiveness of control. Similar rigorous approaches could be applied to many other hazards. Many 
manufacturers' recommendations for the use and maintenance of equipment are also based on the generic characteristics of the user. Using operating data as a basis for performance improvement would be extremely beneficial. The opportunity for a quantitative approach to risk based on data collection would provide the industry with "near real-time" performance indicators and more appropriate prediction tools than the quality tools currently used.

4. Second, mining relies heavily on complex technologies - permanent mining facilities and large mobile equipment and support services - often in isolated and hostile environments. They provide a unique opportunity to collect maintenance data that, in turn, could be analyzed and used to proactively improve the performance of the equipment being tracked. Appropriate data, properly collected using a taxonomic approach, would provide a direct picture of safety, health and technical and economic performance. This knowledge can be used to the advantage of the mining company.

5. It is clear that the above perspectives can also be applied to a much wider spectrum than just safety. The mining industry operates a large number of extremely complex electro-mechanical equipment which, by their nature, are prone to a failure of the mechanisms, which, after analysis, would provide the correct input data in the quantitative risk analysis.

6. The implementation of quantitative risk analysis could be considered as a strategy of resilience in business and conversion of data into management actions, as an inspirational concept that would significantly improve the safety, environmental and operational performance of the mining industry.

\section{References}

1. R.I. Moraru, G.B. Băbuţ, L.I. Cioca, Proceedings of the 13th SGEM GeoConference on Science and Technologies in Geology, Exploration and Mining - SGEM 2013, I, 731-738 (2013)

2. Moraru, R.I., Băbuţ, G.B., Proc. of the 14th Int. Multidisciplinary Scientific Geoconference SGEM 2014, Volume III, pp. 497-504, Albena, Bulgaria, 17-26.06.(2014).

3. R.I. Moraru, G.B. Băbuţ, L.I. Cioca, Conference on Manufacturing Science and Educations - MSE 2011, Volume 2, pp. 363-366, Sibiu, Romania (2011)

4. E. Ben-Awuah, O. Richter, T. Elkington, Y. Pourrahimian, Int. J. of Mining Science and Technology, 26(6), 1065-1071, (2016).

5. A. Desroches, Concepts et méthodes probabilistes de base de la sécurité. Editions Lavoisier TEC\&DOC, Paris, (1995)

6. F.P. Less, Loss Prevention in Process Industries (vol. I, II), Butterworths, London, U.K., (1980)

7. A. Gaureanu, A. Drăghici, H. Weinschrott, Quality - Access to Success, Vol. 20, pag. 141-146, supplement: $\mathbf{1} /(2019)$

8. G.B, Băbuţ, R.I., Moraru, Proceedings of the $16^{\text {th }}$ International Multidisciplinary Scientific GeoConference (SGEM 2016): Science and Technologies in Geology, Exploration and Mining, Volume 2, pp. 635-642, Albena, Bulgaria, 30.06-06.07, (2016)

9. L. Ivaşcu, L.I., Cioca, The $2^{\text {nd }}$ International Conference on Psychology, Management and Social Science, Psychology, Management and Social Science, Shenzhen, China, Book Series: Advances in Education Research, Volume 49, pp.77-80 (2014)

10. N. J. Duijm, Safety Science, 76, 21-31, (2015)

11. R.I. Moraru, G.B. Băbuț, M. Popescu-Stelea, Quality - Access to Success, 17 (151), 92-99, (2016)

12. HSE, Principles and guidelines to assist HSE in its judgements that duty-holders have reduced risk as low as reasonably practicable. Health and Safety Executive, 2002, Available at http://www.hse.gov.uk/dst/alarp1.htm. Accessed: 08.02.2021. (2002)

13. Y.D. Jo, B.J. Ahn, J. Hazard Mater; 123: 1-12, (2005)

14. V.K. Gupta, J.J. Thakkar, Sādhanā 43, 116, (2018) 
15. L.I., Cioca, R.I., Moraru , G.B., Băbuţ, Proceedings of the $15^{\text {th }}$ International Scientific Conference „,The Knowledge Based Organization”, vol. 2, section: Management, pp. 43-48, Land Forces Academy Sibiu, Romania (2009)

16. CEI/IEC, Techiques d'analyse de la fiabilité des systemes. Procédure d'analyse des mod de défaillance et leurs effets (AMDE). CEI 812:1985)

17. R.I. Moraru, Occupational Health and Safety: University Handbook (in Romanian), Universitas Publishng House, Petroşani, (2013)

18. R.I. Moraru, G.B. Băbuţ, Quality - Access to Success Journal, 11, Issue 4, pp. 50-59, (2010)

19. M. Hammar, What to include in risk management methodology according to ISO 45001:2018, March 21, 2019, Accessed the 5 February 2021, https://advisera.com/45001academy/blog/2019/03/21/what-to-include-in-risk-managementmethodology-according-to-iso-45001/, (2019)

20. N. Azadeh-Fard, A. Schuh, E. Rashedi, J. A. Camelio, Safety Science, 76, 160-167, (2015).

21. P. K. Marhavilas, D. Koulouriotis, V. Gemeni. Journal of Loss Prevention in the Process Industries, 24(5), 477-523, (2011)

22. M. Sari, A. S. Selcuk, C. Karpuz, H. S. B. Duzgun, Safety Science, 47(1), 78-87, (2009).

23. D. Hillson, Int. J. Proj. Manag. 20: 235-240, (2002)

24. D. P. Brown, Journal of Mathematical Economics, 69,7-11, (2017)

25. L. Comberti, M. Demichela, G. Baldissone, Safety Science, 106, 191-202, (2018)

26. L. Ivaşcu, L.I., Safety, 5 (1), Article Number: 12, Published: FEB 22, (2019)

27. R.I., Moraru, G.B., Băbuţ, L.I., Cioca, Proceedings of the $17^{\text {th }}$ International Conference - The Knowledge-Based Organization: Management and Military Sciences, pp. 735-740, Sibiu, Romania (2011) 